\title{
Education for Sustainable Development (ESD) in China's Local Primary Schools: A Pilot Study
}

\author{
By Ronghui (Kevin) Zhou ${ }^{1}$
}

\begin{abstract}
This study discusses the current status of ESD implementation in three primary schools and examines factors that have impacted the implementation of ESD in a district of an urban Chinese cities. Semistructured interviews were conducted with three primary school principals and three school teachers. Thematic analysis was used to analyze the data. Three themes emerged that have impacted ESD implementation in this pilot study are discussed: the definition of ESD, lack of local education support, and exam pressures. The results suggested that ESD is underdeveloped in the selected context of urban China. Further investigation is required to capture the whole scope of ESD implementations in China's primary education.
\end{abstract}

Keywords: Education for Sustainable Development; Primary Education; Case Study; Teacher and Principal; China

\section{Introduction}

The concept of Sustainable Development (SD) was developed in response to the last few decades of growing concerns about and awareness towards the future of our world. Along with other countries who are active in supporting the development of SD internationally, China, established the "Agenda 21" in 1994. The Agenda paper listed China's sustainable development goals for the next decades with a focus on three aspects: social, economic, and environmental. Even though China's Agenda 21 presumes that "economic development is a prerequisite for social advancement and environmental protection," the publication of this plan marked the first time that development and sustainability were mentioned together in China's policy, indicating the upcoming government attention and domestic agenda with an eye towards this issue (Bradbury \& Kirkby, 1996, p.106).

In response to the global agenda concerning $\mathrm{SD}$, education was remarkably named the key to fostering sustainable development (McBeath et al., 2014). In response, countries have since developed policies and programs in the education system to foster the concept of Education for Sustainable Development (ESD). Two programs - the Environmental Educator's Initiative (EEI) and the Education for Environment, Population, and Sustainable Development (EPD) - were launched in the late 1990s in China. These two programs aimed to develop Environmental Education (EE) and later became the basis for ESD in the education system in the form of teachers training, ESD experiment schools, and curriculum design. By the end of 2007, 86 primary and middle schools served as pilot schools for the implementation of ESD and environmental education curriculums, and more than 5000 teachers were trained under the EEI program in China (Lee \& Huang, 
2009). The EPD program, which was supported by the United Nation and the Ministry of Education of China, achieved more than 1000 "ESD Pilot Schools" from 14 provinces in China by the end of 2009 (Lee \& Huang, 2009).

While reports have shown the drastic development of ESD in China over the years, some researchers such as Wang (2011) and Han (2015) have suggested gaps in the actual ESD practices as implemented in schools. They point to a lack of ESD awareness among local practitioners and stakeholders as well as an absence of consistent government and institutional support in local contexts (Han 2015). Inadequate teachers training and financial barriers have also restricted the development of ESD in China (Wang, 2015). Therefore, this study aims to reveal the status quo of ESD development in primary schools in an urban city in China. This study draws from school principals and teachers to illustrate their views and roles in implementing ESD. This article will first connect with existing literature regarding ESD and school practices in China and will then detail the study design. Analysis and discussion to explore the findings from the interview will follow.

\section{Literature Review}

In 2016, there were a total of 178,000 primary schools in China, with about 100 million primary school students (Ministry of Education of the People's Republic of China, 2016). Only a small portion of the school and student population had experience with ESD based on the UN ESD school data. Even though programs like EEI and EPD were developed and supported by the government, there are no national policies for ESD in China (Han, 2015). The official Outline of China's National Plan for Medium and Long-term Education Reform and Development 2010-2020 (2010) has listed sustainable development as one of the top education priorities; however, no further explanation or action plan described the implementation of this approach. The lack of government and policy support has meant that there are only a few local stakeholders who promote ESD practice in schools (Han, 2015).

In addition, the absence of specific policies and institutional support has limited opportunities for teacher training on ESD. Even within the limited existing opportunities, there are no official guidelines for training teachers, which brings into question the quality of the ESD training programs (Han, 2015; Wang, 2015). There are also regional disparities in ESD development, as more economically developed regions are more capable of and engaged in ESD implementation while less economically developed regions lack the incentives and resources to deploy ESD initiatives (Han, 2015).

Aside from the absence of ESD policies, case studies in China's schools have also shown gaps in ESD curriculum and pedagogy implementation. Interview results from the "ESD demonstration school" of Jingshan in Beijing, China have shown that there is a lack of guidance from the education department about how to integrate ESD effectively (Witoszek, 2018). These interviews indicated the limited development of ESD on campus despite the fact that Jingshan school was one of the first labeled ESD schools in China (Witoszek, 2018). In Guangzhou, schools were only able to integrate ESD into biology and geography classes, and the results were insignificant, as "half of the interviewed Chinese students were not sure what sustainable development meant” (Witoszek, 2018, pp.837). 
Similar barriers also encountered in Guo et al. (2018)'s research, who investigated ESD in geography education in middle school in China. Guo et al. (2018) gathered data from 237 geography teachers from most provinces of China, surveyed 246 students about ESD practices, and investigated geography textbooks for explore ESD implementation in geography education. Through content analysis on the textbooks, they revealed 26 themes of SD were identified in the textbook but most of the SD contents were brief, and these contents were often portrayed as activity or reading material (Guo et al., 2018). Most teachers were able to identify SD and ESD, and teach these contents in various ways not simply following instructions on the book (Guo et al., 2018). In term of the teaching outcome, survey results shown that "... most students were familiar with people, resources, environmental problems, and climate change, however... [they] were unable to grasp the factual knowledge about SD (Guo et al., 2018, pp.3909)." Teacher trainings, textbooks design, and curriculum innovation, as Guo et al. (2018) argued, are insufficient to promote better ESD practice outcomes in geography education in China. Most importantly, the lack of basic infrastructure for geography activities have reduced students' chances to participate in geography education and further restricted efforts in promoting ESD in schools (Guo et al., 2018).

\section{Methods}

This study was designed towards a case study with qualitative characteristics. Semi-structured interviews were conducted in three local primary schools. The selected primary schools are in the same district of a tier-one city in China (Tier-one cities are economically advanced and politically-centered). All of the selected schools were built after 2013. Two male and one female school principals and three male school teachers participated the study.

School principals play a key role not only in school administration but also in performing their education philosophies in schools. School principals have the autonomy to experiment with different ideals and methods in their schools; therefore, their perspectives towards ESD serve as the foundation for the development of ESD in primary schools. School teachers are also important local education stakeholders, and their experiences in teaching formulate unique pedagogies that are suitable to the local contexts. Teachers' perspective towards ESD can be examined to help further illustrate the feasibility and practicality of the approach in the actual teaching. Furthermore, comparing and contrasting principals' and teachers' perceptions will help to capture the holistic picture of ESD implementation in the selected local primary schools in China.

\section{Analysis}

Only limited ESD or ESD-related practices were found in the selected schools. A common ESD-related practice across schools is environmental education. All of the selected schools provide various classes other than the core subjects, such as art class and drawing class, to not only develop numerical fluency and literacy, but also to help students develop other competencies. In the Science class, students had lessons in environmental protection and climate change outcomes. Waste classification activities on campus, where 
students were taught the importance and outcome of waste classification systems, were also evidences of ESD. Principal C's school even hold a Drawing Competition on waste classification to develop children's environmental awareness. However, school principals and teachers were unable to identify and illustrate examples of the social and economic aspects of ESD. Three themes were emerged that have impacted the development of ESD in schools: ESD definition, local education support, and exam pressures.

\subsection{ESD Definition}

Only one out of the three school principals had heard about the concept of ESD prior the interview, and all school principals understood ESD to be defined differently (See Table 1). None of these principals was able to identify the whole scope of ESD. For example, Principal B only identified the environmental aspect of ESD but did not link it with social and economic factors. However, all principals have positive views towards their understanding of ESD and believe their perceived ESD approach will help prepare students for the next stage of education. To the school teachers, none of the them have heard the concept of ESD. With regard to the definition of ESD, teachers identified ESD as a 'mental and psychological health', 'brain education', and 'physical education' approach to promote physical and mental health of students (See Table 1).

Table 1 Principal's ESD Definition

\begin{tabular}{llll}
\hline & Principal A & Principal B & Principal C \\
\hline ESD & Life-long learning process & Environmental & An approach to develop all-around \\
Definition & and ability; adult education & education & competencies for students \\
& Teacher A & Teacher B & Teacher C \\
ESD & Mental/psychological health & Brain & Physical Education \\
Definition & & Education & \\
\hline
\end{tabular}

\subsection{Local Education Support}

Throughout the interview, both groups of participants have illustrated the frustration towards the lack of the local education support, including ESD events, ESD training workshops, and shifting education priorities. ESD events, such as touring the municipal environmental education center, were limited. Only 1 out of the 3 schools had a chance to visit a local environmental education site this year. The other two schools did not have a chance to visit a local environmental education center due to arrangement reasons. In term of ESD training workshops, two teachers have told the author that they wish to attend ESD workshops or conferences to learn more about ESD. In reality, there are limited opportunities for school teachers and most of these workshops are non-ESD related. For school principals, none of them have attended any conferences or meetings in related to ESD.

In regard to education priorities, all school principals have expressed concerns towards the inconstant education priorities in the education system. The local education department had shifted education priority away from exam preparation a few years ago due to regulating policies. All principals have stated they had articulated new education interests for the schools to replace intense exam preparation for students. However, the recent education reform have brought back the emphasis on exam scores, which in other words 
forced school principals and teachers to restore their education focus towards exam preparation. According to principal B, "they say this today... and tomorrow they want to do something else... I have to follow them, you know, because they are the Education Bureau and I am the school principal..."

\subsection{Exam Pressures}

Both groups of interview participants agree that the intense exam pressures from the education system have deeply affected their education practices. In other words, many of the education interests and practices have been restricted due to the over emphasis of exam scores. All principals revealed that the priority in their schools is preparing students for the secondary school entrance test due to the recent exam reform in the city. In public, the local education department announces to promote quality education and advocate allaround development for students. Two principals have revealed that bureau from the education department asked the school privately to achieve higher exam score. As a result, school principals have to fulfill the needs of the local education department, both quality education and exam expectation, and compromise their autonomy in shaping the education interests and priorities of the school. Teachers, on the other hand, have to follow the principal's education priorities in school

According to Principal B, They say we have to ensure our education quality for the students. You know... they also tell me their exam expectation for our school's exam score in private...' School Principal A cancelled all minor subject classes for the $6^{\text {th }}$ grade students this year. Only Chinese, Math, English, and Science classes are provided for students because these subjects will be tested in the exams. According to Principal A, 'I can't do much since I have to have to make sure we [the school] meet the exam expectation... My education philosophy is to cultivate children their ability to enjoy arts, beauty, you know...' Given the current emphasis on testing in the district, principals are not always able to fully practice their autonomy in their schools regardless of their personal beliefs and educational approaches.

School teachers have also expressed their concerns towards the exam pressures. For example, Teacher $\mathrm{B}$, a $6^{\text {th }}$ grade math teacher, mentioned the intense workload not only for the teachers but also for the students. The most obvious change has been the in-class hours, which have gone from four classes a day to six or more. This has resulted in more math exercise sheets for students and more grading work for teachers. As a result, many student-centered learning pedagogical techniques, such as class discussion, were abandoned due to time consumption of these activities.

\section{Discussion and Conclusion}

Based on the interview data, ESD in the selected primary schools is underdeveloped. As mentioned earlier, only limited ESD approaches have been implemented in these schools due to a number of limitations. Three factors that have affected ESD implementation in primary schools have been revealed. Despite the limited ESD practices in the selected primary schools, both principals and teachers hold positive views towards the approach and believe in the essential role of sustainability concepts in education. ESD pedagogical approaches_-such as student-centered learning and competency-focused training-were also highly supported by both principals and 
teachers. However, principals are primarily concerned with the practicality and feasibility of the approach in the existing education system and near future, whereas teachers indicated a stronger belief that ESD has the potential to prepare students for the future world.

The interview data shows that both principals and teachers were unable to capture the full scope of ESD in their understandings of the concept. This raise the question of the definition of ESD in China's contextual setting. Even though the United Nations has promoted the concept of ESD in the macro sense, countries often focus on a particular theme or several concepts which are suitable to their specific cultural, social, and political setting. For example, Vietnam has established national policies regarding SD with a specific focus on modernization and industrialization, even though the technical term 'ESD' is not been widely used there (Nguyen, 2018). Currently, ESD is seen as environmental education in the selected primary schools. However, there is no national policy or other official statement have linked ESD with environmental education, or stating the definition of ESD in China. Even though programs such as EPD have helped spread influence of ESD in China throughout the last decade, these efforts have been hampered by the limitations of China's education policies.

The blurred definition of ESD also indicates that there is lack of ESD training or workshops for education stakeholders in the selected sites. Without sufficient workshops and meetings for educating ESD to education stakeholders, ESD would not be fully understand and implemented at education sites. Providing necessary ESD trainings, workshops, or conferences to stakeholders would promote ESD in local schools (Han, 2015). Additionally, an official training manual or guideline is needed to ensure the quality of these trainings (Han, 2015). For ESD to gain traction in primary education, supports are required for the local education department and education stakeholders. Given the sophisticated existing education system in China, ESD experts need to create a feasible ESD framework that takes this model into account. Even though EPD projects have supported ESD implementation in more than 1000 schools in China, this study and other field studies have indicated that these ESD practices may not be as robust as desired (Wang, 2011; Witoszek, 2018).

Exam pressures have been widely discussed across China over last decades. Even though China tried to proceed with education reform which aimed to provide 'quality education' and develop children with all-around abilities in 2002, exams have maintained their pivotal role regardless of any efforts made to change the education system (Yan, 2012). Evidence from the interviews with principals and teachers has shown the importance of exams and suggests that other educational approaches are minimized in favor of a test-based approach. The overemphasis on exam preparation also implies the restriction of the principals' autonomy in exercising their education interests and philosophy. The education department evaluates school principals, which means that principals' career advancement depends on the formal or informal tasks given by the education department. As a result, school principals are compelled to fulfill the education department's demands regardless the costs. Similarly, teachers are under pressure to follow the instructions given by their principals. In order to implement ESD in schools, it is critical that all levels of stakeholders in a given area recognize the importance and the potential impacts of sustainability values. Further education policy support is required to support ESD implementations in schools. 
Overall, this study has explored ESD in three primary schools in a city in China. Through the perspectives of school principals and teachers, this study has identified barriers that impact the implementation of ESD in schools. The results of this study indicate the underdevelopment of ESD in the selected schools in China. A further detailed and comprehensive study is required to investigate the ESD implementation gaps in China's primary education.

\section{References}

Bradbury, I., \& Kirkby, Richard. (1996). China’s Agenda 21. Applied Geography, 16(2), pp.97-107.

China. Ministry of Education. (2016). Summary of Education in China. Available at: http://www.moe.gov.cn/jyb_sjzl/s5990/201711/t20171110_318862.html

Han, Q. (2015). Education for Sustainable Development and Climate Change Education in China: A Status Report. Journal of Education for Sustainable Development, 9(1), pp.62-77.

Lee, Chi-Kin., \& Huang, Yu. (2009). Education for Sustainable Development Project and Curriculum Reform in China: the EEI and the EPD. In: C, Lee., \& M, Williams., eds., Schooling for Sustainable Development in Chinese Communities: Experience with Younger Children. New York: Springer., pp. 115-135.

McBeath, G., McBeath, J., Qing, T., and Yu, Huang. (2014). Environmental Education in China's Primary and Middle Schools. Cheltenham: Edward Elgar Publishing Ltd, pp.33-56.

Nguyen, Phuong. (2018). Education for Sustainable Development in Vietnam: exploring the geography teachers' perspectives. International Research in Geographical and Environmental Education, 27(4), pp.342-357.

Outline of China's National Plan. 2010. Outline of China's National Plan for Medium and Long-term Education Reform and Development 2010-2020. Retrieved from: http://uil.unesco.org/fileadmin/keydocuments /LifelongLearning/en/china-2010-abstract-lll-strategy.pdf

Wang, Q. (2011). Characteristics of ESD-Promoting Strategies in China's Basic Education. Journal of Education for Sustainable Development, 5(2), pp.215-223.

Wang, W. (2015). An Exploration of Patterns in the Practice of Education for Sustainable Development in China: Experience and Reflection. Open Journal of Social Science, 3, pp.64-75.

Witoszek, N. (2018). Teaching sustainability in Norway, China and Ghana: challenges to the UN programme. Environmental Education Research, 24(6), pp.831-844.

Yan, C. (2012). "We can only change in a small way': A study of secondary English teachers' implementation of curriculum reform in China." Journal of Educational Change, 13, pp.431-447. 